Article

\title{
Sustainable Aging and Leisure Behaviors: Do Leisure Activities Matter in Aging Well?
}

\author{
Hyejin Yoon ${ }^{1}$, Lesa Huber ${ }^{2}$ and Chulwon Kim ${ }^{3, * \mathbb{D}}$ \\ 1 Department of Hotel and Tourism, Baewha Women's University, Seoul 03039, Korea; hyejin@baewha.ac.kr \\ 2 Department of Applied Health Science, School of Public Health, Indiana University, \\ Bloomington, IN 47405, USA; lehuber@indiana.edu \\ 3 College of Hotel and Tourism Management, Kyung Hee University, Seoul 02447, Korea \\ * Correspondence: kimcw@khu.ac.kr; Tel.: +82-2-961-0816; Fax: +82-2-961-0811
}

Citation: Yoon, H.; Huber, L.; Kim, C. Sustainable Aging and Leisure Behaviors: Do Leisure Activities Matter in Aging Well? Sustainability 2021, 13, 2348. https://doi.org/ $10.3390 /$ su13042348

Academic Editor: Giuseppe Battaglia

Received: 13 January 2021

Accepted: 17 February 2021

Published: 22 February 2021

Publisher's Note: MDPI stays neutral with regard to jurisdictional claims in published maps and institutional affiliations.

Copyright: (c) 2021 by the authors. Licensee MDPI, Basel, Switzerland. This article is an open access article distributed under the terms and conditions of the Creative Commons Attribution (CC BY) license (https:// creativecommons.org/licenses/by/ $4.0 /)$.

\begin{abstract}
A substantial portion of the gerontological literature has been directed towards the relationship between leisure and aging, particularly with the healthy life of older adults. The concept of leisure conveys varied meanings to persons, including identifying the leisure itself, the activity's frequency, and its value to the participant. With increased longevity, the concept of aging well and related terms (e.g., "active aging", "successful aging", "productive aging", "positive aging", "healthy aging", and "sustainable aging") have been emerging themes for academic fields related to gerontology, exercise promotion, health care, and leisure activities. Thus, the aging population and human leisure activities must be considered sustainable as sustainability is primarily human-centered. This study explores older adults' perceptions of leisure and aging well and their leisure behavior at senior welfare centers using qualitative data collection and methodology. Findings suggest that four main themes emerge: unfamiliarity with the concept of leisure and leisure engagement; evolving perceptions of senior centers and leisure benefits; limited physical functioning as a major leisure constraint; perceptions of major factors for aging well. Implications for researchers and policymakers are discussed.
\end{abstract}

Keywords: aging well; leisure; sustainability; sustainable aging

\section{Introduction}

The aging population is one of the demographic changes in the 21st century. The World Tourism Organization (UNWTO) advocated that preparing for the economic and social shifts associated with an aging population is essential to ensure progress towards achieving the goals outlined in the 2030 Agenda for Sustainable Development [1]. Trends in population aging are particularly relevant for the Sustainable Development Goals (SDGs) related to eradicating poverty and ensuring healthy lives and well-being at all ages. This global trend of aging populations leads to new demands on individuals, families, communities, and societies such as well-being and life, healthcare demand, social and financial security, housing, and accessible environments [2]. Therefore, the aging population should be considered from a sustainability perspective since the social demands are related to the major dimensions of sustainability, which is primarily a human-centered approach [2]. Additionally, the existing literature generally represents a small part of the entire picture of the aging population from developed countries' cases; therefore, future research should concentrate on developing countries' aging situation [3].

With increased longevity, the concept of aging well and related terms (e.g., "active aging", "successful aging", "productive aging", "positive aging", "healthy aging", and "sustainable aging") have been emerging themes for academic fields related to gerontology, exercise promotion, health care, and leisure activities [2-10]. Aging well continues to be redefined and reimagined, although gerontology studies have focused on the nature of aging well for more than fifty years [7-9]. However, there is no common definition or 
conceptualization of aging well in gerontology studies [4,7-9]. This concept has been criticized because of semantics, difficulty in operationalizing variables, and other theoretical problems [4]. For example, those who do not meet the physical, psychological, and social criteria of aging well could be unfairly defined as unsuccessful, unhealthy, or unproductive [10]. Nevertheless, these studies would help investigate what factors could be a significant problem or solution by letting older adults rate their aging success. It could also be a helpful tool to distinguish between older adults who are experiencing a high quality of life and those who are not [10].

Numerous aging studies have shown that participation in meaningful leisure activities rather than sedentary leisure, including physical (e.g., exercise), social (e.g., club activities), and productive (e.g., volunteering) activities, is a significant predictor of successful aging and well-being [5,11-13]. The longitudinal study of "Aging Well" by Geroge. E. Vaillant also confirmed the importance of leisure activity after retirement, particularly how to spend leisure time with whom and which activity is clearly linked with aging well in later life [11]. While a substantial portion of the literature has been directed towards aging well, mainly related to older adults' physical and cognitive function and social engagement, there is not much research that addresses leisure behavior and aging well in older adults from a sustainability perspective.

Therefore, this study approaches the meaning of older adults' leisure and aging well through an emic perspective and will describe their concept of aging well. To explore the perceptions of leisure and aging well and how leisure relates to aging well, a qualitative study using an individual in-depth interview was conducted. The ultimate goal of this research is to initiate a discussion about the role of leisure in aging well for current and future older adults. By identifying the role of leisure activity in aging well in Korea's case, this research will provide some insight into how policymakers and leisure practitioners could assist older people in developing countries in making a smooth transition into life after retirement.

\section{Literature Review}

\subsection{Aging Population and Sustainability}

The increasing size of the aging population is the most crucial factor affecting sociodemographical changes in the world. The number of people aged 65 or more is expected to increase from approximately 420 million in 2000 to 974 million in 2030 [14]. This demographic change has a strong influence on sustainable development because people's health outcomes, social needs, and values should also be changed [15]. Various challenges are also being faced across national, community, and individual levels [3]. Under this circumstance, many countries have recently paid attention to sociocultural issues and individuals' well-being for sustainable development [2]. Grazuleviciute-Vileniske and his colleagues suggest that the aging population and related challenges should be considered from a sustainable perspective. Therefore, supporting the growing older population by first understanding older people's needs and situations and then taking multisectoral action on aging well are critical in achieving the goal of sustainable development.

The concept of aging well and related terms such as successful aging, active aging, healthy aging, positive aging, and productive aging can be identified from a sustainable perspective. For example, WHO (2021) posits that "a commitment to the Sustainable Development Goals (SDGs) means a commitment to Healthy Ageing and a commitment to taking concerted actions to formulate evidence-based policies across all sectors that strengthen the abilities of older persons" [15]. To implement healthy aging in SDGs, WHO focuses on the following principles [15]:

- (Goal 1. No poverty) preventing older people from falling into poverty;

- (Goal 2. Zero hunger) achieving food security and improved nutrition;

- (Goal 3. Good health and well-being) ensuring healthy lives and promoting well-being for all at all ages; 
- (Goal 4. Quality education) providing inclusive and quality education for all and promoting lifelong learning;

- (Goal 5. Gender equality) achieving gender equality and empowering all women and girls;

- (Goal 9. Industry, innovation, and infrastructure) building resilient infrastructure, promoting inclusive and sustainable industrialization, and fostering innovation;

- (Goal 10. Reduced inequality) Reducing inequality within and among countries;

- (Goal 11. Sustainable cities and communities) making cities and human settlements inclusive, safe, resilient, and sustainable;

- (Goal 16. Peace, justice, and strong institutions) promoting just, peaceful, and inclusive societies for sustainable development, providing access to justice for all, and building effective, accountable institutions at all levels.

Healthy aging for sustainable development is a more holistic approach that includes physical, economic, social, and subjective well-being and the meaning of later lives. Living environment, infrastructure, and social policies are very important for aging well. However, numerous research studies have mainly focused on the objective, physical, and environmental well-being of older adults. The definition of sustainable aging is frequently used in that the physical environment enables older people to continue independence in later life. This sustainability is associated with lifestyle, institutional issues, and the physical living environment $[2,16,17]$. Little is known about healthy lives and well-being in later life. Therefore, the research related to sustainable aging needs to focus more on older adults' well-being and social inclusion [2].

\subsection{Aging and Leisure: South Korea's Case}

Aging is associated with role loss in family, the workplace, and society, decreased biological, physical, and cognitive function, loss of companions, and mortality [14]. Leisure replaces work as a vehicle for finding meaning in one's life and assists individuals in making a smooth transition into life after retirement $[5,13,18]$. Previous research has studied programs to promote well-being and maintain better capacity for older adults. Leisure, particularly leisure time exercise, has been considered a powerful intervention in older adults for aging well, particularly for decreased depression $[18,19]$ and enhanced health status [20], life satisfaction [21], and other outcomes (e.g., improved physical functioning or psychological well-being, reduced mortality) $[22,23]$.

The same can be said for productive and social leisure engagement. For example, volunteerism of older adults has long been considered a productive activity [24]. Studies have shown a positive relationship between volunteering and older participants' physical and mental health $[25,26]$. Volunteering impacts social integration and reduces social isolation and loneliness after retirement and loss of family and social roles.

Despite the importance of active leisure engagement and increased free time in later life, many older Koreans do not participate in leisure activities outside their homes. According to preliminary data on older Koreans' leisure participation in 2017, Koreans aged 65 years and older had $7 \mathrm{~h}$ of leisure a day, even though their free time was the highest among all age groups. The national survey also showed that watching television was the most common leisure activity (99.3\%), followed by taking a walk $(27.5 \%)$ and participating in other activities to some extent, including social gathering, hiking, gardening, taking a nap, and chatting [27]. Approximately $72 \%$ of older adults did not engage in leisure activities in their daily lives; only 3 to $8 \%$ of them participated in active leisure activities such as sports/cultural activities and travel [27].

\subsection{South Korea as an Aged Society and Older Adults' Leisure}

Korea has one of the fastest-growing older populations in the world. In 1960, the number of people over the age of 65 represented approximately 2.9 percent $(0.7$ million) of the total Korean population; in 2019, this cohort has grown to 15.5 percent (8.02 million) [28]. Korea became an aging society in 2000, defined as a country where 7 percent or more of 
the population is 65 and over, and an aged society in 2018, where 14 percent or more of the population will be 65 and over. It is predicted to become a super-aged society in 2024, in which 20 percent or more of the population will be 65 and over [28]. This fast growth of the older population is hardly seen anywhere else in the world. It took Japan 36 years to change from an aging society to a super-aged society, compared with 47 years for the UK, 72 years for the U.S., and 115 years for France [28]. Surprisingly, Korea is expected to complete this transition from an aging society to a super-aged society within 25 years-an even faster rate than Japan.

In contrast with the better health status of older Koreans, their quality of life is much lower than other countries'. The suicide rate of older Koreans is the highest among OECD member countries; older adults have higher levels of depression symptoms, loneliness, and suicide rate than other age groups in Korea [13]. Considering the role of leisure activities in aging well, the lack of physical, social, and productive activities in older Korean adults may lead to lower levels of subjective well-being and aging well.

Although the Korean Ministry of Health and Welfare (2018) provides a snapshot of how Koreans currently spend their available free time, quantitative study offers little insight into the opportunities, constraints, or attitudes older Koreans might perceive as optimal use of free time and their association with aging well. In this research, we seek to understand how leisure participants are involved with leisure activities in later life, contributing to life satisfaction and enjoying a sustainable life, aging well. We developed the following research questions to guide the work: How do older Korean adults get involved in leisure activities outside their home? How do older adults describe their leisure experiences and successful aging during later life? How do they perceive leisure benefits and outcomes?

It is critical to understand older adults' perceptions of leisure and aging well and the role of leisure in their lives as policies and programs for older adults begin to attempt to meet the aging population's rapid growth [13].

\section{Methods}

\subsection{Design and Participants}

An exploratory study using individual in-depth interviews was conducted in June and August 2013 and January 2021 in three senior welfare centers in Seoul, Korea's capital city. This qualitative study had a two-stage research process to confirm the first stage research results and find a new perspective on sustainable aging and leisure. We assume that today's older adults may change their perceptions and attitudes towards leisure and aging well because Korean baby boomers born between 1955 and 1963 are entering later life from 2020 onwards and have higher education and income level than the former generation.

Purposive sampling, a non-probability sampling technique widely utilized when researchers need a deliberate choice of an informant because of the qualities the research participant possesses [29], was used to recruit participants according to the following criteria: (1) Korean senior center participant, (2) 65 years and older without psychological disorders such as dementia, delirium, or schizophrenia, (3) able and willing to talk about their life and thoughts and communicate well with a researcher. Korea has accepted the chronological age of 65 years as a definition of an older person, similar to many developed countries; therefore, people aged 65 and older were selected for this study.

The snowball sampling technique was also utilized to meet potential participants. The staff of the three centers introduced the researcher to their female service representative to help visitors and senior participants as a volunteer. These assistants were the first person at each center to participate in the interview, and then they introduced other interviewees. This sampling method helped to access a hard-to-reach targeted sample and to collect data smoothly [30]. In the first investigation, eight participants were included: six female and two male older adults. In the second investigation, four seniors were interviewed: two female and two male older adults. They ranged in age from 65 to 75 (average age: 68.9 years old), and all resided in Seoul. Recruitment ceased when new additional findings 
and themes did not emerge among the senior center participants [31]. As for the research population and sample size, Creswell (2013) suggested that it is essential to determine the sample size when selecting participants for a qualitative study. A recommended sample size of participants is between 2 and 25, who have a "similar lived experience of the phenomenon being studied" (p. 156) in phenomenological research tradition [32].

The personal interview particularly has numerous benefits for qualitative data collection. This method is well suited to explore attitudes, values, motives, or beliefs of respondents and has better response rates than a survey [33]; therefore, this interview method is appropriate to understand older adults' feelings, perceptions, and attitudes and to find meaning from their voices. Interview guidelines, strategies, and rules were based on standard interview techniques [33].

A semi-structured interview is particularly well suited to obtain more informative and clear answers by probing respondents' perceptions and opinions about complex issues [34]. The investigator can use and develop a key interview question and topic that needs to be covered during the interview [33]; this guideline helps a researcher discover comparability through semi-structured interview data. Thus, research data were collected by utilizing semi-structured interviews, which asked participants about their leisure experiences and perceptions of aging well, and episodic interviews in order to encourage active expressions of participants' thoughts and feelings (Table 1). The interview initially had the following questions, but these were modified according to the participants' response and interview context. All interviews were conducted by a Korean researcher and took place in a quiet and private room in the centers in order to avoid any interruptions and to protect confidentiality. The interviews usually began with a warm-up time to build rapport with the participants and lasted approximately 50-60 $\mathrm{min}$, based on an appropriate length of interview for respondents [33].

Table 1. Interview questions.

Questions
$\begin{gathered}\text { Episodic Interview } \\ \text { Please explain your normal daily schedule and life. } \\ \text { Dow does this activity benefit you as an older person? } \\ \text { Hemi-structured } \\ \text { Interview }\end{gathered} \quad \begin{array}{r}\text { What do you think about the senior center? Is it good for your LOHAS } \\ \text { (Lifestyle of Health and Sustainability)? }\end{array}$
If you do not have any favorite leisure activity, what is the reason?
What constraints prevent you from participating in leisure activities?
Have you ever heard the phrase "aging well"? Just tell me your idea how
you can age well in your sustainable lives.
Are you satisfied with your life now?

\subsection{Ethics and Reflexivity}

The researcher explained the purpose of this research, our position and institutional affiliation, the privacy and confidentiality of research participants, and other ethical concerns related to human subjects research. Participants were read a study information sheet, provided oral informed consent, and received a small cash incentive before completing the interview. A cash incentive may encourage research participation, but may not be the only important factor for older Koreans in this study. For example, several older people indeed refused to become involved in this study despite the monetary incentive because they tended to believe that they did not deserve to participate in a "study". They were shy about expressing their thoughts in front of the researcher who has a higher level of education, and they often worried about the quality of their words. The researcher had to reveal their position and the research to the older people under the guidelines of ethics, but this position (education level and institutional affiliation) was a significant challenge 
for data collection and the relationship with this group. Therefore, the researcher paid much attention to field relations and being reflexive regarding the positionality and power relation between a researcher and participant that influence research methods, findings, and interpretations as well as ethical issues.

\subsection{Data Analysis}

Each interview was recorded and then transcribed immediately at the end of the interview. The transcripts were analyzed using NVivo 7.0. NVivo is a computer software tool for effective qualitative transcription and analysis [35,36], which was employed to store, sort, classify, and arrange the interview data so that the themes and hidden meanings of this research emerged. Using software in the data analysis process is to add rigor to qualitative research [37]. Debate on the usefulness of the concepts of validity and reliability in qualitative research has been undertaken for many years [37]. Qualitative research has used terms such as "trustworthiness", "rigorousness", or "quality of the data". The NVivo software program is designed to facilitate interrogation of the data in a thorough and transparent manner [38].

Coded text segments were read line-by-line by a single researcher to decipher initial codes into noticeable themes. Emergent themes were analyzed for similarities and differences by constant comparison method to identify patterns and themes and ensure rigor $[31,39]$. Consequently, distinct themes and quotes were presented in this research.

\section{Findings and Analysis}

Participants provided insights into contemporary older Koreans' perceptions of leisure and its role in aging well. Four main themes emerged from the data analysis: unfamiliarity with the concept of leisure and leisure engagement, evolving perceptions of Korean senior centers and leisure benefits, limited physical function as a major leisure constraint, and major factors for successful aging in Korean older adults (see Figure 1). Research findings include participant quotes as supportive illustrations.

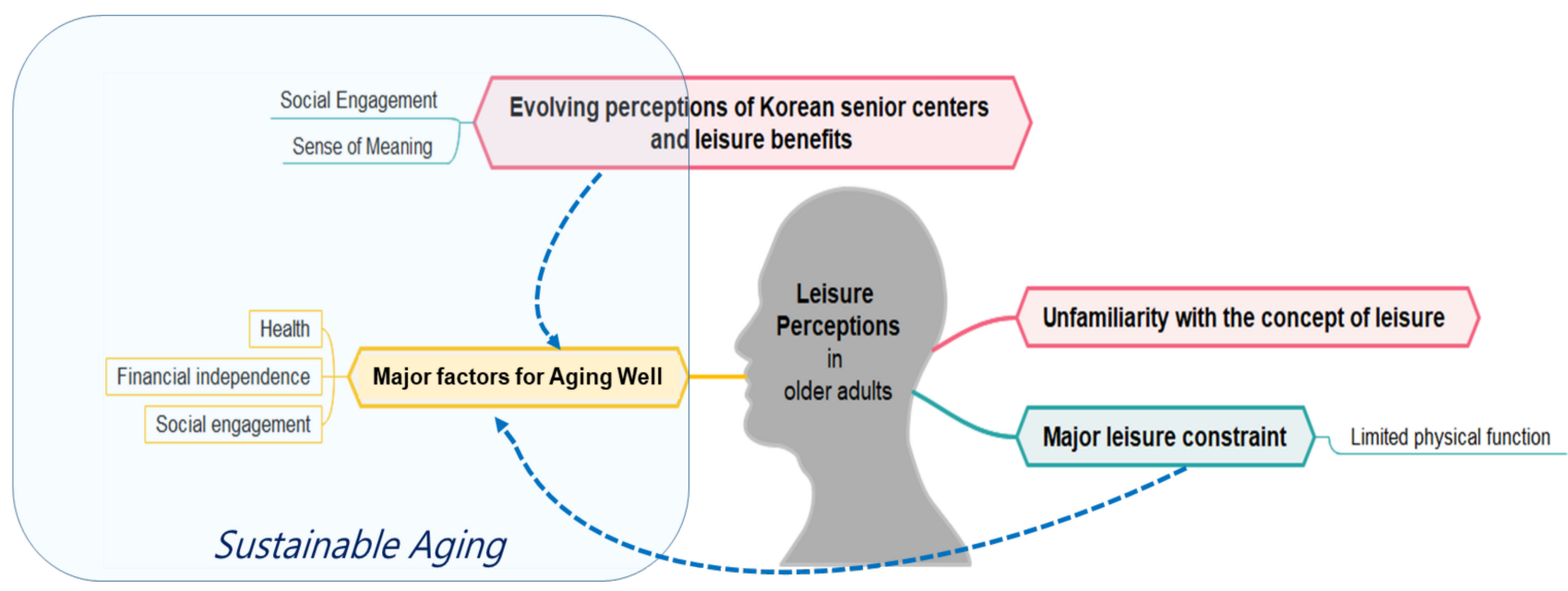

Figure 1. Research findings of leisure perceptions in aging seniors.

\subsection{Unfamiliarity with the Concept of Leisure and Leisure Engagement}

The terms leisure (called Yeo-Ga in Korean) and leisure engagement are unfamiliar for current older people. Interview participants asked, "Leisure? What is leisure?" when discussing this study and their leisure activities in later life. Consequently, it was difficult for participants to imagine or associate something immediately and easily with the word leisure. The researcher had to explain the term for participants' understanding (e.g., What do you do in your free time at home or outside? What are your most enjoyable activities during your free time?). 
"I've never heard the terms leisure and leisure activity. ... Honestly, I have no idea which activity is good for me and my later life both to maintain health and spend a day pleasantly. I had spent so much time watching T.V. before I decided to come to this center."

"When I was young, I was really busy every day. In the morning, I had to prepare for my husband going to work and for my children going to school. ... But, now it is different. My kids have moved out and my role at home disappeared. Even worse, I have nowhere special to go and nothing special to do. There is nowhere welcoming older people and I feel really lonely. ... I am sad because I am treated like a useless old person."

\subsection{Evolving Perceptions of Senior Centers and Leisure Benefits}

Most respondents were initially reluctant to be involved in senior centers. Their initial perceptions of senior centers were of a place for people who were poor, did not live with their family, or were otherwise very disadvantaged.

"At first, truthfully, for some reason I was embarrassed to come to this place. I thought I would look poor so I did not like going. ... On parents' day, my daughter-in-law suggested I go to the senior center to eat lunch and I got angry-am I a beggar who cannot find food? I thought the senior center was a place where people who had nothing to do, had no money, and were not respected by their children went to spend time."

Although the respondents were hesitant to attend senior centers, older adults' children, daughters-in-law, and friends tend to become a key agent of leisure socialization for older Koreans. They encouraged respondents to spend time with their peers rather than staying at home alone. With encouragement, these participants overcame their initial discomfort and found various benefits from participation in leisure activities at the centers.

In analyzing the theme of leisure benefits, two subthemes emerged: social engagement and finding meaning.

\subsubsection{Social Engagement}

Respondents reported that they enjoyed meeting people who have similar physical conditions and feelings about aging. Respondents sometimes felt a huge generation gap with young people and even their children and felt isolated from their children's family. However, they reported that friends who meet at the senior center better understand their thinking and opinions about lifestyle and ideology than their children. Even they had a strong sense of belonging to their cohort by overcoming dynamic social problems. Thus, respondents perceived the benefit of social engagement through senior center participation.

"In fact, some people really irritate me. However, I just tolerate them because I just want to enjoy my time more interestingly. ... Above all, I am really happy because I am a member of my peer group and I feel a sense of belonging through involvement in leisure programs and meetings. ... Therefore, I used to come to the meeting days in spite of poor physical conditions. When I meet my friends, I strongly realize they really welcome me."

\subsubsection{Sense of Meaning}

Participants reported feeling new energy and joy after meeting new friends and enjoying leisure activities at the center. They have also experienced a sense of meaning, including self-esteem and confidence, and perceived that meaningful leisure engagement promotes a wide range of quality of life.

"I'm learning a Korean traditional instrument, Janggu (which is an hourglass-shaped drum). I finally know how to play "Arirang" and other traditional songs. At first I made the mistake of feeling embarrassed about it. Not now. My playing has improved a lot and I'm so satisfied and proud of myself. Yes! I gain self-confidence from this activity. I'm not a useless old person anymore. I am useful and feel greatly appreciated because of that." 


\subsection{Limited Physical Function as a Major Leisure Constraint}

Participants reported about their physical condition causing difficulty when doing things in their daily lives, especially enjoying exercise and going outside. They discussed general and specific functional limitations that were perceived as barriers to leisure engagement. Due to age-related limitations, they stressed the importance of health in aging well. They also noted the lack of age-appropriate exercise programming at the senior center, particularly for relatively older people.

"I know exercise is good for my health because it's always on television. But it's not easy. ... When it gets cold, I don't want to go outside and when it rains, I'm not comfortable. Especially those days, my bones hurt. My physical condition is not good. ... I feel exercising is burdensome."

\subsection{Major Factors for Aging Well (LOHAS)}

The term "aging well" for older adults is not familiar. The term related to aging well is not generally used in Korea, although it has been translated in Korean research. Thus, the researcher had to rephrase the term aging well in order to describe older adults' own ideas and practices for aging well: "What do you think the important factors are to live happy and age well in your LOHAS (Lifestyle of Health and Sustainability)?"

First of all, health emerged as a very important factor to successful aging. Participants reported that they were likely to experience age-related changes such as physical and psychological problems as they age. Respondents thought they were becoming less adept at performing routine tasks. Such health-related problems motivated the participants to be actively involved in exercise and to be interested in diet, health promotion, and health food supplements. Some of them also believed that their poor health and disease could cause financial and caregiver burden on their sons/daughters. Thus, they were likely to exercise regularly in order not to be a burden on their children.

"Health is the most important thing of all. What good are money and success when I lose my health? When I lose my health, I cannot do anything. So, keeping my health should be my top priority and thus, I have always participated in group exercise with my friends at this center."

Next, participants commonly reported the importance of achieving financial independence from their sons/daughters and supporting their children for their happiness. Although the Korean parent-child relationship and the endless support of Korean parents were very unique as a factor of successful aging, many responses involved this theme. Respondents believed that their financial status plays a key role in maintaining a good (or bad) relationship with their sons/daughters and sons-/daughters-in-law in later life. They also wanted to support their children both physically and emotionally for serving the needs of children after retirement, although their sons/daughters were already independent of their parents. They regarded the successful and happy life of their children as their own success and happiness.

"I' $m$ a happier man than other friends because I'm not beholden to my children. I really believe older adults should have economic ability enough to live on by ourselves, as we get older... In fact, money helps the relationship between parents and their children in later life get along better and fewer fights take place. Most friends who have no economic ability feel slighted from their sons/daughters and sons-/daughters-in-law. However, if older parents have financial power, children never abuse or neglect their parents. Anyway, money is very important- to eat everything I want to eat and to enjoy fun activities in later life."

The third factor for aging well was the importance of social engagement and an active life. Many participants reported that social engagement and activity (e.g., participating in various leisure activities at the senior center, gathering with family/friends, and traveling) gave them something to do in their daily lives. Such a purposeful life brought greater happiness and health to respondents who felt fulfilled from meaningful activities. 
"To be happy, older adults should have positive thinking. But if we stay at home all day without any social activities and contacts, we never form such positive ideas. So, I really recommend social engagement, especially joining various activities, clubs, or programs at senior centers, to other friends who are staying at home in front of a television."

From their own perspectives, older adults define "aging well" as including the three major components of "health, financial independence, and active later life and social engagement".

\section{Discussion and Conclusions}

This qualitative research is aimed at investigating seniors' perceptions of their leisure activities at senior welfare centers and the meaning of aging well. The findings show four interrelated themes: unfamiliarity with the leisure concept and leisure engagement; evolving perceptions of senior centers and leisure benefits; limited physical function as a major leisure constraint; and major factors for aging well. The major factors of aging well include good health, financial independence, and social connection through activities.

This research reveals that current older Koreans have little understanding of both the terms leisure and aging well, and how to engage with meaningful leisure activities in later life. One possible reason is that older adults in particular did not experience a 40-h, five-day work week system, first introduced in 2004 in Korea. When these respondents were working adults, Korean society focused predominantly on the country's economic growth and labor productivity, more than an individual's leisure and happiness, in order to create an economic base after the Korean war. Thus, older people had to work hard and did not have time to devote to anything else. It means that they did not have an opportunity to learn how to socialize through leisure from their parents, friends, or education during their childhood $[13,40]$. The lack of previous leisure activities in social situations negatively influences current leisure behavior and aging well in the older Korean generation. In this context, respondents had no idea how to enjoy leisure happily and healthily without having to work and care for children; they perceived loneliness and lower life satisfaction before they participated in activities at the leisure facilities.

Previous studies have confirmed that meaningful leisure engagement replaces work as a vehicle for finding meaning in one's life and assists individuals in making a smooth transition into life after retirement; this is a critical factor for aging well $[5,13,18-26,41]$. In a recent study, Canhan et al. (2018) argue that "the social contexts of aging are important to an individual's ability to age well and have their psychosocial needs met, or conversely, impede one's ability to thrive" (p. 140). Thus, active leisure involvement will be a significant prescription for solving social problems related to Korea's aging demographic, particularly lower life satisfaction and subjective well-being. Additionally, the current social issue of Korea will be an implication for developing countries that focus on economic growth without considering individuals' life satisfaction. For example, rapid economic growth did not increase Koreans' happiness and life satisfaction; this case of Korea regarding the relationship between life satisfaction and GDP is an interesting outlier in worldwide data [42]. Older Koreans also fail to meet the "paradox of aging" that "despite the aging-associated loss of fertility and a decline in physical health, subjective well-being and happiness increase after middle age" (p. 318) [43]. Consequently, the role of leisure engagement in raising life satisfaction and aging well cannot be overlooked in developing countries.

Additionally, research findings suggest that senior welfare centers can be a meaningful place for older people to connect with society, relieve their loneliness and depression, meet their peers, and experience various leisure/recreation activities. They contain the meaning of lifestyle of health and sustainability (LOHAS). This finding supports previous studies that senior center involvement provides positive social, physical, and mental well-being, especially for lonely older people $[44,45]$. Common spaces for older adults could offer various opportunities for social interaction, physical activities, and engaging in recreational activities, thus enhancing the older adults' well-being [41].

This finding also confirms that senior centers are the best place to meet similar-age older adults and interact with them. Current older Koreans tend to have more conservative 
ideologies and lifestyles than the younger generations and feel a strong sense of belonging with their cohort since they have been exposed to democratization and industrialization processes. This result supports the subculture of aging and the age stratification theory that older adults sustain their social identities and self-concepts through membership in a subculture; they prefer socializing within their own cohort over other age groups because they have similarities through shared backgrounds, interests, and problems $[14,46]$. The concept of sense of coherence (SOC) developed by Antonovsky within the salutogenetics theory also could be applied in the specific context of healthy and sustainable aging [47]. The SOC refers to the orientation an individual has to understand a particular situation, use available resources, and consider the meaning of their challenges [47,48]. Antonovsky's salutogenetic approach offers a helpful framework of mental and physical health, focusing on the various elements at play in maintaining a healthy state of being. Therefore, further research needs to investigate older adults' specific situation, constraints, mental and physical health, and aging well within this framework.

However, it is not yet clear how older Koreans were convinced actually to participate in the centers for the first time and to extend their leisure activities in daily life. Thus, further investigation is needed to elaborate on this social mechanism. Moreover, Korean senior welfare centers need to be developed for older adults and baby boomers, since insufficient facilities, boring programs, and negative perceptions about senior centers can be a structural constraint to participating in meaningful leisure activities in later life. Policymakers and leisure providers, therefore, should consider this issue by redesigning the leisure facilities and programs.

This study also finds that older Korean people regard health, financial independence, and active later life and social engagement as significant aspects of aging well. Although this definition has some intrinsic limitations to measure it and generalize in the entire population of older Koreans, it would be helpful to see what factors are most important for sustainable aging by asking older Koreans to think about their own success and happiness in later life and to compare the important criteria of aging well with other countries. For example, the components of health and social engagement are consistent with previous research related to aging well [3-10]. However, interestingly, the financial relationship with adult children may be culturally unique. Korean parents are culturally obligated to pay for educating children and for their children's weddings [49]. Our interviewees wanted to support their children financially and emotionally beyond their education and weddings; they also regard healthy finances as a necessity for maintaining a good relationship with children. Indeed, those who can provide support for their children and grandchildren were more satisfied in later life than those who receive financial support from their children. This finding is consistent with Kim and Kim (2000) who showed that older Koreans who can greatly support their children were more satisfied with life than those who could not, in general [50]. In this context, the successful and happy lives of their children are seen as the influential factor of older Koreans' successful later life.

In addition, respondents regarded an active life and social engagement through meaningful leisure activities as a major factor for sustainable aging. This would imply that older people could have leisure skills, knowledge, and motivation by educating and encouraging them to be involved in leisure activities; those who participate in meaningful leisure perceive a multitude of benefits in sustainable aging, although current older adults, in particular, have not experienced leisure socialization throughout their lifetimes and might have no idea how to enjoy leisure activities in later life. This perceived value from their own experiences would be a good start to make a foundation for their sustainable aging. The words of a research participant gave us an insightful message:

"My son and daughter-in-law gave me a dinner show ticket as my birthday gift. So, I firstly participated in the concert and had a great dinner. After enjoying the show for the first time in my life, I couldn't forget the great fun time and memories. So, I sometimes go to a concert and theater to enjoy it again, although I am not very well off and have to save pocket money from my son and daughter. Unfortunately, I am just beginning to 
enjoy such an activity in my seventies. I realize leisure activities give me great energy and induce positive thinking. I believe it's never too late to have a very nice day. 70s is not an old age. ... I am also learning how to use the Internet at this center. Once I can use the Internet well, I hope I can search my favorite songs and shows via the Internet and involve myself in fan sites (laughing)."

This qualitative study has several limitations, although it does contribute to highlighting the important role of meaningful leisure engagement in sustainable aging. First, research participants lived in a capital city and were healthy volunteers; they generally could access better leisure services and opportunities than those who live in rural areas and have some physical/mental limitations. Thus, little is known about older adults who live in rural areas, have limitations, and are involved in sedentary activity; a future investigation is needed to overcome this issue. Additionally, prospective cohort or panel studies should explore meaningful trends regarding leisure and sustainable aging from the contemporary to future older generations, since the leisure behaviors and attitudes of the better-educated baby boomers and future generations are likely to be different to current older adults. Future studies might also fruitfully explore the motivation behind the initial participation in senior centers to develop policies and programs to serve aging populations.

Author Contributions: Conceptualization, literature review, analysis and writing, H.Y.; review and editing, supervision, L.H.; writing, review and editing, infrastructure support, C.K. All authors have read and agreed to the published version of the manuscript.

Funding: This research received no external funding.

Conflicts of Interest: The authors declare no conflict of interest.

\section{References}

1. World Tourism Organization (UNWTO); United Nations Development Programme (UNDP). Tourism and the Sustainable Development Goals-Journey to 2030. Spain: UNWTO. 2017. Available online: https://www.e-unwto.org/doi/pdf/10.18111/9 789284419401 (accessed on 27 December 2020).

2. Grazuleviciute-Vileniske, I.; Seduikyte, L.; Teixeira-Gomes, A.; Mendes, A.; Borodinecs, A.; Buzinskaite, D. Aging, Living Environment, and Sustainability: What Should be Taken into Account? Sustainability 2020, 12, 1853. [CrossRef]

3. Kudo, S.; Mutisya, E.; Nagao, M. Population Aging: An Emerging Research Agenda for Sustainable Development. Soc. Sci. 2015, 4, 940-966. [CrossRef]

4. Chapman, S.A. A 'New Materialist' Lens on Aging Well: Special Things in Later Life. J. Aging Stud. 2006, 20, 207-216. [CrossRef]

5. Dupuis, S.L.; Alzheimer, M. Leisure and Ageing Well. World Leis. J. 2008, 50, 91-107. [CrossRef]

6. Michel, J.P.; Sadana, R. "Healthy aging" Concepts and Measures. J. Am. Med Dir. Assoc. 2017, 18, 460-464. [CrossRef]

7. Pruchno, R.; Carr, D. Successful Aging 2.0: Resilience and Beyond. J. Gerontol. Ser. B 2017, 72, 201-203. [CrossRef]

8. Rantanen, T.; Portegijs, E.; Kokko, K.; Rantakokko, M.; Törmäkangas, T.; Saajanaho, M. Developing an Assessment Method of Active Aging: University of Jyvaskyla Active Aging Scale. J. Aging Health 2019, 31, 1002-1024. [CrossRef]

9. Reich, A.J.; Claunch, K.D.; Verdeja, M.A.; Dungan, M.T.; Anderson, S.; Clayton, C.K.; Goates, M.C.; Thacker, E.L. What Does "Successful Aging" Mean to you?-Systematic Review and Cross-Cultural Comparison of Lay Perspectives of Older Adults in 13 Countries, 2010-2020. J. Cross Cult. Gerontol. 2020, 35, 455-478. [CrossRef]

10. Strawbridge, W.J.; Wallhagen, M.I.; Cohen, R.D. Successful Aging and Well-being: Self-rated Compared with Rowe and Kahn. Gerontologist 2002, 42, 727-733. [CrossRef]

11. Vaillant, G.E. Aging Well: Surprising Guideposts to a Happier Life from the Landmark Harvard Study of Adult Development; Little Brown: Boston, MA, USA, 2002.

12. Kim, M.J.; Kim, W.G.; Kim, J.M.; Kim, C. Does Knowledge Matter to Seniors' Usage of Mobile Devices? Focusing on Motivation and Attachment. Int. J. Contemp. Hosp. Manag. 2016, 28, 1702-1727. [CrossRef]

13. Yoon, H.; Lee, W.S.; Kim, K.-B.; Moon, J. Effects of Leisure Participation on Life Satisfaction in Older Korean Adults: A Panel Analysis. Int. J. Environ. Res. Public Health 2020, 17, 4402. [CrossRef]

14. Hooyman, N.R.; Kiyak, H.A. Social Gerontology: A Multidisciplinary Perspective, 9th ed.; Pearson: New York, NY, USA, 2011.

15. WHO. Healthy Ageing and the Sustainable Development Goals. 2020. Available online: https://www.who.int/ageing/sdgs/en/ (accessed on 12 January 2021).

16. Landorf, C.; Brewer, G.; Sheppard, L.A. The Urban Environment and Sustainable Ageing: Critical Issues and Assessment Indicators. Local Environ. 2008, 13, 497-514. [CrossRef]

17. $\mathrm{Wu}, \mathrm{W}$; Kaushik, I. Design for sustainable aging: Improving design communication through building information modeling and game engine integration. Procedia Eng. 2015, 118, 926-933. [CrossRef] 
18. Henning, G.; Stenling, A.; Bielak, A.A.; Bjälkebring, P.; Gow, A.J.; Kivi, M.; Muniz-Terrera, G.; Johansson, B.; Lindwall, M. Towards an Active and Happy Retirement? Changes in Leisure Activity and Depressive Symptoms during the Retirement Transition. Aging Ment. Health 2020, 1-11. [CrossRef] [PubMed]

19. Lee, H.-Y.; Yu, C.-P.; Wu, C.-D.; Pan, W.-C. The Effect of Leisure Activity Diversity and Exercise Time on the Prevention of Depression in the Middle-Aged and Elderly Residents of Taiwan. Int. J. Environ. Res. Public Health 2018, 15, 654. [CrossRef] [PubMed]

20. Hicks, S.A.; Siedlecki, K.L. Leisure Activity Engagement and Positive Affect Partially Mediate the Relationship between Positive Views on Aging and Physical Health. J. Gerontol. Ser. B 2017, 72, 259-267. [CrossRef] [PubMed]

21. Argan, M.; Argan, M.T.; Dursun, M.T. Examining Relationships Among Well-being, Leisure Satisfaction, Life Satisfaction, and Happiness. Int. J. Med. Res. Health Sci. 2018, 7, 49-59.

22. Barengo, N.C.; Antikainen, R.; Borodulin, K.; Harald, K.; Jousilahti, P. Leisure-time Physical Activity Reduces Total and Cardiovascular Mortality and Cardiovascular Disease Incidence in Older Adults. J. Am. Geriatr. Soc. 2017, 65, 504-510. [CrossRef]

23. Bragina, I.; Voelcker-Rehage, C. The Exercise Effect on Psychological Well-being in Older Adults-A Systematic Review of Longitudinal Studies. German J. Exerc. Sport Res. 2018, 48, 323-333. [CrossRef]

24. Hansen, T.; Aartsen, M.; Slagsvold, B.; Deindl, C. Dynamics of Volunteering and Life Satisfaction in Midlife and Old Age: Findings from 12 European Countries. Soc. Sci. 2018, 7, 78. [CrossRef]

25. Lim, S.E.R.; Cox, N.J.; Tan, Q.Y.; Ibrahim, K.; Roberts, H.C. Volunteer-led Physical Activity Interventions to Improve Health Outcomes for Community-Dwelling Older People: A Systematic Review. Aging Clin. Exp. Res. 2020, 1-11. [CrossRef]

26. Morrow-Howell, N.; Lee, Y.S.; McCrary, S.; McBride, A. Volunteering as a Pathway to Productive and Social Engagement Among Older Adults. Health Educ. Behav. 2014, 41, 84S-90S. [CrossRef]

27. Ministry of Health and Welfare. Korean Elderly Life Conditions and Welfare 2017; Ministry of Health and Welfare: Daejeon, Korea, 2018.

28. Statistics Korea. Report on South Korea and World Population Prospects 2019; Statistics Korea: Daejeon, Korea, 2019.

29. Tongco, M.D.C. Purposive Sampling as a Tool for Informant Selection. Ethnobot. Res. Appl. 2007, 5, 147-158. [CrossRef]

30. Jackson, M.; White, G.; Schmierer, C. Tourism Experiences within an Attributional Framework. Ann. Tour. Res. 1996, 23, 798-810. [CrossRef]

31. Glaser, B.; Strauss, A.L. The Discovery of Grounded Theory: Strategies for Qualitative Research; Aldine: Chicago, IL, USA, 1967.

32. Creswell, J.W. Qualitative Inquiry and Research Design Choosing among Five Approaches, 3rd ed.; Sage: Thousand Oaks, CA, USA, 2013.

33. Glesne, C. Becoming Qualitative Researchers: An Introduction, 4th ed.; Pearson: Boston, MA, USA, 2011.

34. Barriball, K.L.; While, A. Collecting Data using a Semi-structured Interview: A Discussion Paper. J. Adv. Nurs. 1994, 19, 328-335. [CrossRef] [PubMed]

35. Dingwall, L.; Mclafferty, E. Do Nurses Promote Urinary Continence in Hospitalized Older People? An Exploratory Study. J. Clin. Nurs. 2006, 15, 1276-1286. [CrossRef] [PubMed]

36. Leech, N.L.; Onwuegbuzie, A.J. Beyond Constant Comparison Qualitative Data Analysis: Using NVivo. Sch. Psychol. Q. 2011, 26, 70-84. [CrossRef]

37. Kelle, U.; Laurie, H. Computer Use in Qualitative Research and Issues of Validity. In Computer-Aided Qualitative Data Analysis: Theory, Methods and Practice; Kelle, U., Ed.; Sage: Thousand Oaks, CA, USA, 1998; pp. 19-28.

38. Welsh, E. Dealing with Data: Using NVivo in the Qualitative Data Analysis Process. Forum Qual. Soc. Res. 2002, 3. Available online: http:/ / www.qualitativeresearch.net/fqs-texte/2-02/2-02welsh-e.htm (accessed on 27 December 2020).

39. Lincoln, Y.S.; Guba, E.G. Establishing Trustworthiness. In Qualitative Research; Bryman, A., Burgess, R.G., Eds.; Sage: London, UK, 1999.

40. Hoff, A.E.; Ellis, G.D. Influence of Agents of Leisure Socialization on Leisure Self-efficacy of University Students. J. Leis. Res. 1992, 24, 114-126. [CrossRef]

41. Canham, S.L.; Fang, M.L.; Battersby, L.; Woolrych, R.; Sixsmith, J.; Ren, T.H.; Sixsmith, A. Contextual Factors for Aging Well: Creating Socially Engaging Spaces through the Use of Deliberative Dialogues. Gerontologist 2018, 58, 140-148. [CrossRef]

42. Easterlin, R.A. Happiness, Growth, and Public Policy. Econ. Inq. 2013, 51, 1-15. [CrossRef]

43. Jeste, D.V.; Oswald, A.J. Individual and Societal Wisdom: Explaining the Paradox of Human Aging and High Well-being. Psychiatry 2014, 77, 317-330. [CrossRef] [PubMed]

44. Aday, R.H.; Kehoe, G.C.; Farney, L.A. Impact of Senior Center Friendships on Aging Women who Live Alone. J. Women Aging 2006, 18, 57-73. [CrossRef]

45. Ha, C.; Kim, H. The Effects of Physical Self-efficacy of Elderly People in Attending the Leisure Facilities and Programs on Life Satisfaction. Korean J. Leis. Recreat. Stud. 2013, 37, 1-12.

46. Minkler, M.; Estes, C.L. Readings in the Political Economy of Aging; Routledge: New York, NY, USA, 2019.

47. Antonovsky, A. The salutogenic model as a theory to guide health promotion. Health Promot. Int. 1996, 11, 11-18. [CrossRef]

48. Lindström, B.; Eriksson, M. Salutogenesis. J. Epidemiol. Commun. Health 2005, 59, 440-442. [CrossRef] [PubMed]

49. The Korea Herald. Education Cost: Government Must Take Up Greater Share. The Korea Herald. 2004. Available online: http:/ / khnews.kheraldm.com/view.php?ud=20140914000332\&md=20140917005149_BL (accessed on 25 December 2020).

50. Kim, J.; Kim, Y. Generational Differences of Social Support and Life Satisfaction. Korean Elder. Res. 2000, 20, 155-168. 